\title{
Universal promotion of heterogeneous olefin metathesis catalysts by controlling dynamic active site renewal
}

\author{
Terry Z. H. Gani ${ }^{1,2}$, Zachariah J. Berkson ${ }^{2}$, Ran Zhu ${ }^{1}$, Jong Hun Kang ${ }^{1}$, John R. Di Iorio ${ }^{1}$, Ka \\ Wing Chan ${ }^{2}$, Daniel F. Consoli ${ }^{1}$, Sohel K. Shaikh ${ }^{3}$, Christophe Copéret ${ }^{2 *}$, Yuriy Román- \\ $\operatorname{Leshkov}^{1 *}$.
}

${ }^{1}$ Department of Chemical Engineering, Massachusetts Institute of Technology (MIT), Cambridge, MA 02139, USA.

${ }^{2}$ Department of Chemistry and Applied Biosciences, ETH Zurich, CH-8093 Zurich, Switzerland.

${ }^{3}$ Research and Development Center, Saudi Aramco, Dhahran 31311, Saudi Arabia.

*Correspondence to: ccoperet@ethz.ch, yroman@mit.edu

Abstract: Olefin metathesis is a versatile strategy for large-scale olefin interconversion, yet mechanistic details over industrial heterogeneous catalysts have remained ambiguous for decades. Here, from rigorous kinetic measurements, spectroscopic studies, and computational modeling of propylene metathesis over model and industrial $\mathrm{WO}_{\mathrm{x}} / \mathrm{SiO}_{2}$ catalysts, we identify a hitherto unknown site renewal and decay cycle, mediated by proton transfers involving proximal Brønsted acidic $\mathrm{OH}$ groups, which operates concurrently with the classical Chauvin cycle. We show how this cycle can be manipulated using small quantities of promoter olefins to drastically increase steady-state propylene metathesis rates by up to 30 -fold at $250^{\circ} \mathrm{C}$ with negligible promoter consumption. The increase in activity and considerable reduction of operating temperature 20 requirements were also observed on $\mathrm{MoO}_{\mathrm{x}} / \mathrm{SiO}_{2}$ catalysts, showing that this strategy is general and can address major roadblocks associated with industrial metathesis processes.

Main Text: As an atom-efficient strategy for the large-scale interconversion of olefins, heterogeneously catalyzed olefin metathesis has seen several commercial applications in the petrochemical, polymer, and specialty chemical industries ${ }^{1-2}$. For instance, the cross-metathesis of ethylene and 2-butenes, known commercially as the Lummus Olefin Conversion Technology $(\mathrm{OCT})$ process ${ }^{1-2}$, is an appealing route for the on-purpose production of propylene to address the $\mathrm{C}_{3}$ shortfall caused by using shale gas as a feedstock in steam crackers ${ }^{3-4}$. The advantages of the OCT process over other on-purpose propylene production technologies, such as propane dehydrogenation ${ }^{3,5}$ and methanol-to-olefins ${ }^{6}$, are that the metathesis reaction is nearly 30 thermoneutral and highly selective ${ }^{1-2}$. However, metathesis has been gradually losing market share to these alternatives: as of 2019 , only ca. $4 \%$ of the world's propylene supply of ca. 130 million metric tons per annum is estimated to be derived from metathesis ${ }^{7-8}$, largely because a suitably active and stable catalyst has yet to be found. In particular, tungsten oxide dispersed on silica $\left(\mathrm{WO}_{\mathrm{x}} / \mathrm{SiO}_{2}\right)$ remains the industrial catalyst of choice over other supported metal oxides (e.g., $35 \quad \mathrm{Re}_{2} \mathrm{O}_{7} / \mathrm{Al}_{2} \mathrm{O}_{3}$, which is active at room temperature but deactivates relatively rapidly) owing to its tolerance to feed impurities and stability over long operating periods ${ }^{9}$, but suffers from low rates of reaction and requires high operating temperatures $\left(\mathrm{ca} .350-450^{\circ} \mathrm{C}\right.$ ). Yet, the increasing demand of propylene has kept metathesis as a key technology in the petrochemical industry, attracting significant academic and industrial interest over the past few decades.

40 Supported metal oxides lack the alkylidene moieties responsible for catalytic activity in homogeneous metathesis catalysts ${ }^{10-11}$. Rather, the active sites on heterogeneous catalysts are 
thought to form in situ from metal-dioxo precursors upon reaction with the olefin substrate at high temperatures $9,12-14$. The kinetically and thermodynamically demanding nature of this activation process ${ }^{12-13}$ results in a very low fraction of catalytically active metal centers, explaining the low reaction rate per unit mass of catalyst and high operating temperature requirement of $\mathrm{WO}_{\mathrm{x}} / \mathrm{SiO}_{2}$, as well as the failure to characterize the reaction intermediates spectroscopically ${ }^{9,15}$. Indeed, activation procedures that promote alkylidene formation, such as high temperature pretreatment under reducing atmospheres ${ }^{16-17}$ or, more recently, pre-reduction with organosilicon reducing agents ${ }^{15,18}$, generate highly active catalysts that operate at low temperatures (e.g., $70{ }^{\circ} \mathrm{C}$ ), but these materials deactivate rapidly for reasons that remain obscure. Furthermore, propylene selfmetathesis reaction orders ranging from 0.8 to 1.8 have been reported ${ }^{13,19-21}$ despite the wellknown Chauvin mechanism ${ }^{10}$ predicting a reaction order less than 1 . These, among other puzzling observations, are symptomatic of broader gaps in the mechanistic understanding of heterogeneous olefin metathesis that have hindered process development.

Here, we present a new mechanistic picture for heterogeneous olefin metathesis, supported by kinetic, spectroscopic, and computational studies, in which the active site count dynamically varies as a result of a site decay and renewal cycle operating in parallel with the Chauvin cycle (Fig. 1, top). More specifically, we show that site decay and renewal are mediated by proton transfers involving Brønsted acidic surface $\mathrm{OH}$ groups. We further show that, by co-feeding substituted olefins that promote active site renewal but are unreactive towards cross-metathesis, this hitherto unknown cycle can be manipulated to significantly increase the steady-state active site population and metathesis rate (Fig. 1, bottom). Our findings not only reconcile longstanding issues in the mechanistic understanding of heterogeneous olefin metathesis, but also reveal a strategy for enhancing the activity and reducing the operating temperature requirement of tungsten- and molybdenum-based metathesis catalysts.

We performed the kinetic studies in a tubular reactor heated under flowing propylene mixed with helium as an inert diluent, operating under differential conditions and in the absence of mass transfer limitations (see Supporting Information for details). For simplicity, we selected propylene self-metathesis into ethylene and 2-butene as our primary probe reaction, and systematically varied the reactor temperature and propylene concentration $\left(300-330^{\circ} \mathrm{C}, 20-50 \mathrm{~mol} \%\right.$ propylene, Figs. $2 \mathrm{~A}-\mathrm{B})$ while measuring product distributions in the reactor effluent through gas chromatography analysis (fig. S1). To avoid the potential confounding effects of metal clusters or interface sites present in classical wet-impregnation catalysts ${ }^{9}$, we used a catalyst prepared by surface organometallic chemistry (SOMC) ${ }^{22}$ consisting solely of isolated W(VI)-oxo surface sites supported on silica ${ }^{15}$ (referred to as 3\%SOMC; figs. S2-4), while benchmarking important results against an industrial $\mathrm{WO}_{\mathrm{x}} / \mathrm{SiO}_{2}$ catalyst prepared by wet impregnation ${ }^{15}$. We measured a propylene reaction order of 1.9 on $\mathbf{3 \% S O M C}$ (Fig. 2A, orange), confirming the existence of abnormally high reaction orders inherent to isolated tungsten sites. The measured apparent activation energy of $156 \mathrm{~kJ} / \mathrm{mol}$ on $\mathbf{3 \% S O M C}$ (Fig. 2B, orange) is consistent with literature values for supported tungsten catalysts ${ }^{13,20}$, but significantly higher than those computed for tungsten alkylidene complexes (ca. 20-30 kcal/mol) ${ }^{23}$, further hinting at the existence of other kinetically relevant steps beyond the Chauvin cycle. Furthermore, we note that similar kinetic results were obtained over the industrial wet-impregnation catalyst (fig. S5) demonstrating the similitude between the systems (vide infra for further comparison).

Analysis of transient kinetic behavior provides clues as to the nature of these additional steps. As observed early on for classical supported $\mathrm{WO}_{\mathrm{x}}$ catalysts ${ }^{24}$, the initial approach to steady-state for 
the 3\%SOMC catalyst was marked by an extended induction period of ca. 24-48 hours (fig. S6) and attributed to slow olefin- and silanol-mediated ${ }^{12}$ reduction of $\mathrm{W}(\mathrm{VI})$-dioxo sites to W(IV)oxo sites ${ }^{12-13,15}$. This site formation process has been noted to be roughly first-order in propylene 24. A helium purge of the system at steady-state led to a second, shorter, induction period of ca. 12 hours to return to the original steady-state rate (fig. S7), suggesting that the active sites are unstable in the absence of propylene, presumably decaying into an inactive resting (off-cycle) state, and are regenerated upon re-exposure to propylene. A similar response time resulted from a step change in reaction temperature at steady-state (fig. S8). We thus surmised that the steady-state active site fraction varies with reaction conditions as a result of dynamic site decay and renewal. Indeed, overall second-order kinetics can be recovered by assuming the fraction of active sites is proportional to the propylene partial pressure, as might be expected from combining first-order metathesis with first-order site renewal and zero-order site decay steps.

The existence of a distinct site decay and renewal cycle operating in parallel to the Chauvin cycle holds important mechanistic implications. If site renewal and metathesis are indeed separate processes, then the olefins used to regenerate the active sites need not be the same olefins that undergo metathesis. Such asymmetry between the ability of the olefin to participate in active site generation or in the metathesis reaction is observed in ethylene/2-butene cross-metathesis, which exhibits the same greater-than-first-order behavior as its reverse reaction (i.e., propylene selfmetathesis), but with an ethylene order of 0.7 and a 2-butene order of 1.0 (fig. S9). This difference in reaction orders between the two reactants cannot be explained by differences in their metathesis reactivity, but is instead consistent with 2-butene being more efficient than ethylene at active site renewal to the extent that it becomes responsible for maintaining active sites in the nominally equimolar cross-metathesis system.

The further realization that site renewal and decay rates contribute to the steady-state metathesis rate provides a new handle to improve catalyst efficiency that is orthogonal to traditional catalyst design efforts. In particular, co-feeding an olefin more adept at regenerating or preserving sites than the reactant(s) should improve steady-state catalyst performance by increasing the steadystate population of active sites. A striking example of this phenomenon is the paradoxical increase (by $1.5 \mathrm{x}$ ) in steady-state propylene self-metathesis rate upon addition of 2-butene to the feed (fig. S10), which runs counter to the expectation that degenerate 2-butene self-metathesis should instead inhibit the reaction by competing for active sites. However, this observation is in fact consistent with 2-butene participating in kinetically relevant site renewal without altering Chauvin cycle intermediates.

The practical feasibility of this promotion strategy hinges on the discovery of a promoter olefin that is not only highly active for site renewal, but also selective against deleterious side reactions forming by-products that would complicate downstream separation. Indeed, a promotion of propylene metathesis was first observed in the 1970 s by Phillips Petroleum workers ${ }^{25}$, but the polyene promoters investigated then decomposed under reaction conditions. To this end, we screened a set of 1,1-disubstituted olefins that do not readily undergo cross-metathesis ${ }^{26}$ for their ability to promote propylene metathesis. All olefins tested increased steady-state propylene metathesis rates by varying degrees, confirming the generality of our promotion strategy (Fig. 1, bottom). A $1.5 \mathrm{~mol} \%$ concentration of the best-performing promoter, 2,3-dimethyl-1-butene (i4ME), increased steady-state propylene metathesis rates by nearly 5 -fold at $330^{\circ} \mathrm{C}$ and 30 -fold at $250^{\circ} \mathrm{C}$ (Fig. 2C). The formation of unwanted side products, including isobutene, 2-methyl-2butene (3ME) and unidentified $\mathrm{C} 7$ and $\mathrm{C} 8$ hydrocarbons, was minimal, with a $<1 \%$ selectivity 
relative to the formation rates of metathesis products at $250^{\circ} \mathrm{C}$ (table $\mathrm{S} 1$ ). Despite facile interconversion of i4ME and its positional isomer 4ME (2,3-dimethyl-2-butene) under reaction conditions (table S2), 4ME is also a competent promoter and we expect a steady-state intermediate promotion factor would be attained if the promoter is continuously separated and recycled, as would be expected in an industrial process.

We performed a series of mechanistic studies to probe the pathways of active site renewal and decay and explain how promoter olefins alter this balance. First, the reaction rate reverts to its original steady-state value upon stopping promoter flow (Fig. 2C), confirming that the promoter does not irreversibly alter active sites. Next, a control experiment showing temporary promotion upon exposure of a purged catalyst to $4 \mathrm{ME}$ (fig. S11) confirms that adsorbed promoter molecules, rather than promoter molecules in the gas phase, are responsible for the promotional effect. Kinetic studies performed in the presence of promoter molecules further show that co-feeding $1.0 \mathrm{~mol} \%$ $4 \mathrm{ME}+0.5 \mathrm{~mol} \%$ i4ME decreases the propylene reaction order from 1.9 to 0.7 at $330^{\circ} \mathrm{C}$ (Fig. $2 \mathrm{~A}$ ), accompanied by a combined promoter reaction order of 0.8 (fig. S12). This result suggests that the promoter reduces the dependence of the active site fraction on propylene concentration. The promoter also decreases the apparent activation energy by $40 \mathrm{~kJ} / \mathrm{mol}$ to $119 \mathrm{~kJ} / \mathrm{mol}$ (Fig. 2B), rationalizing the dramatic increase in promotion factor at lower temperatures $\left(<300^{\circ} \mathrm{C}\right)$.

We then used in situ diffuse reflectance infrared Fourier transform spectroscopy (DRIFTS) to better understand how olefinic substrates and promoters interact with the catalyst surface. Exposure of spent $3 \% \mathrm{SOMC}$ to propylene at $50^{\circ} \mathrm{C}$, followed by purging of gas-phase and physisorbed hydrocarbons under flowing $\mathrm{N}_{2}$, yielded a broad series of peaks in the $\mathrm{sp}^{3} \mathrm{C}-\mathrm{H}$ stretching region (Fig. 3A). The relative peak intensities are characteristic of chemisorbed isopropoxy species ${ }^{12}$ likely created here by a Brønsted acid-base reaction involving propylene and a silanol group with increased acidity induced by a proximal tungsten site (fig. S13) ${ }^{27}$. The presence of strong acid sites is directly confirmed by solid-state $1 \mathrm{D}{ }^{15} \mathrm{~N}\left\{{ }^{1} \mathrm{H}\right\}$ CPMAS NMR analysis of the precatalysts after reaction with ${ }^{15} \mathrm{~N}$-labeled pyridine as a probe molecule (fig. S14). As would be expected from a reversible and exothermic adsorption process, the DRIFTS signals rapidly decay upon heating of the chemisorbed surface under $\mathrm{N}_{2}$ (fig. S15). Propylene exposure at $350^{\circ} \mathrm{C}$ resulted in a virtually identical spectrum to that obtained from exposure at $50^{\circ} \mathrm{C}$, suggesting that isopropoxide formation remains the dominant catalyst-substrate interaction even under reaction conditions (fig. S16). Chemisorption of other olefins also yielded similar absorption bands, again attributable to alkoxide formation, with intensities increasing in the order ethylene $<<$ propylene, 2-butene $<4 \mathrm{ME}<$ i4ME (Fig. 3B and fig. S17). This trend can be rationalized in terms of increasing ease to generate the carbocation upon olefin protonation and subsequently the surface alkoxide species. This trend also matches that of promotional ability (table S3), highlighting the importance of Brønsted acidic silanols in modulating the dynamic balance between site renewal and decay. Indeed, early experiments demonstrated that steady-state propylene metathesis rates can be increased by poisoning these acidic sites, whether reversibly by co-feeding ammonia ${ }^{28-29}$ or irreversibly by introducing a silylating agent ${ }^{30}$.

40 The formation of surface alkoxide species is further corroborated by solid-state $1 \mathrm{D}$ and $2 \mathrm{D}{ }^{1} \mathrm{H}$ and ${ }^{1} \mathrm{H}\left\{{ }^{13} \mathrm{C}\right\}$ magic angle spinning (MAS) NMR. 3\%SOMC was activated thermally and subsequently contacted with i4ME and propylene (see Supporting Information for details). ${ }^{1} \mathrm{H}$ MAS NMR signals are detected at 0.6, 1.0, 1.6, and 5.4 ppm (Fig. 4), which are resolved based on their different correlations to ${ }^{13} \mathrm{C}$ signals in the solid-state $2 \mathrm{D}{ }^{1} \mathrm{H}\left\{{ }^{13} \mathrm{C}\right\}$ dipolar-mediated heteronuclear multiple quantum coherence (D-HMQC) NMR correlation spectra of the post-reaction catalyst 
(Fig. 4). Specifically, the ${ }^{1} \mathrm{H}$ signals at $0.6,1.0$, and $1.6 \mathrm{ppm}$ are all correlated to a distribution of ${ }^{13} \mathrm{C}$ signal intensity from $20-35$ ppm (green shaded region in Fig. 4), which we assign to a distribution of surface alkyl moieties, possibly derived from hydrocarbon products of olefin aromatization and/or cracking. Importantly, the ${ }^{1} \mathrm{H}$ signal at $1.6 \mathrm{ppm}$ is also correlated to a ${ }^{13} \mathrm{C}$ signal at $75 \mathrm{ppm}$ (blue shaded region in Fig. 4), which we assign to surface alkoxide species that are likely bound to the silica support as evidenced by the chemical shift value ${ }^{31}$. An additional correlation is observed between a ${ }^{1} \mathrm{H}$ signal at $5.4 \mathrm{ppm}$ and ${ }^{13} \mathrm{C}$ signals from $20-35$ ppm that likely arises from residual surface-bound olefinic moieties. The alkoxide signal was not observed in the corresponding control experiment without i4ME (figs. S18 and S19), consistent with our DRIFTS studies suggesting that the promoter greatly increases the surface coverage of alkoxide species.

A putative mechanism for Brønsted acid-catalyzed site renewal and decay is the 1,2-proton shift pathway (Fig. 5A) that has been extensively documented for tantalum, molybdenum, and tungsten complexes in the presence of a proton source ${ }^{32-34}$ and proposed for the low-temperature initiation of styrene metathesis on well-defined silica-supported W(IV)-oxo species ${ }^{27}$. This process has been shown to be readily reversible ${ }^{27}$, consistent with the site initiation and decay pathways proposed here. Density functional theory calculations on minimal cluster models of mononuclear $\mathrm{WO}_{\mathrm{x}} / \mathrm{SiO}_{2}$ sites demonstrate the feasibility of this proposal (Fig. 5A), in agreement with recently reported computational results on $\mathrm{MoO}_{x} / \mathrm{SiO}_{2}$ catalyst models ${ }^{14}$. The initial formation of the catalyst resting state, a tungsten alkyl species (3), is thermodynamically favorable and occurs most easily by hydrogen transfer to a $\pi$ complex (2). A subsequent $\alpha$-hydrogen abstraction then yields an alkylidene product (4). Compared to the classical allylic $\mathrm{C}-\mathrm{H}$ activation mechanism that does not invoke proximal silanol groups, these reaction steps lead to a significantly flatter overall energy landscape (Fig. 5A and fig. S20).

A catalytic mechanism integrating the Chauvin cycle with dynamic site renewal and decay, while illustrating a possible role of the promoter olefin, is presented in Fig. 5B. In the absence of promoter, site renewal and decay (blue) are mediated by proximal silanol groups (red) via the hydride shift mechanism described above, resulting in a dynamic balance that governs the fraction of Chauvin cycle intermediates (black) and hence the observed metathesis rate. Disubstituted alkylidenes, such as the isopropylidene pictured, are competent metathesis initiators ${ }^{35}$ and can lead to the main Chauvin cycle after a single turnover (bottom left). Free silanol groups react with promoter olefins to yield the alkoxide and/or carbocation species (green) observed by DRIFTS and solid-state NMR. As acid-base pairs, these species serve as kinetically superior proton transfer agents compared to free surface silanols, akin to the role of $\left[\left(\mathrm{Et}_{2} \mathrm{O}\right)_{2} \mathrm{H}\right]\left[\mathrm{B}\left(\mathrm{C}_{6} \mathrm{H}_{5}\right)_{4}\right]$ as an initiator of molecular Mo- and $\mathrm{W}$-imido metathesis catalysts via a kinetically controlled 1,2-proton shift pathway in which protonation of a $\pi$ complex is rate limiting ${ }^{34}$. Although the precise mechanism by which these acid-base pairs facilitate proton transfers remains under investigation, this mechanism is nevertheless fully consistent with all of our experimental observations detailed above.

The practicality of our mechanism is demonstrated by the reactivity gains obtained using the wetimpregnation catalyst both for the self-metathesis of propylene (fig. S21) and for the industrially relevant cross-metathesis of ethylene and 2-butene (fig. S22). Co-feeding the i4ME promoter over a $15 \mathrm{wt} \% \mathrm{WO}_{3} / \mathrm{SiO}_{2}$ catalyst at $250^{\circ} \mathrm{C}$ resulted in rate increases of ca. 6x and $5 \mathrm{x}$, respectively. While these values are lower than those obtained with the $\mathbf{3 \%}$ SOMC catalyst, they substantiate the use of promoters as a versatile handle to access reaction conditions previously considered impractical for tungsten-based materials. 
Finally, similar reactivity gains and kinetic behaviors are also observed for molybdenum-based materials, confirming that our observations and proposed mechanism are indeed universal. In particular, steady-state propylene metathesis rates increased by ca. 26x and 68x upon co-feeding the $\mathrm{i} 4 \mathrm{ME}$ promoter at $200^{\circ} \mathrm{C}$ over a $1.5 \mathrm{wt} \% \quad \mathrm{MoO}_{3} / \mathrm{SiO}_{2}$ catalyst prepared by $\mathrm{SOMC}$ (1.5\% MoSOMC) and a $1.4 \mathrm{wt} \% \mathrm{MoO}_{3} / \mathrm{SiO}_{2}$ catalyst prepared by wet impregnation respectively (fig. S23). 


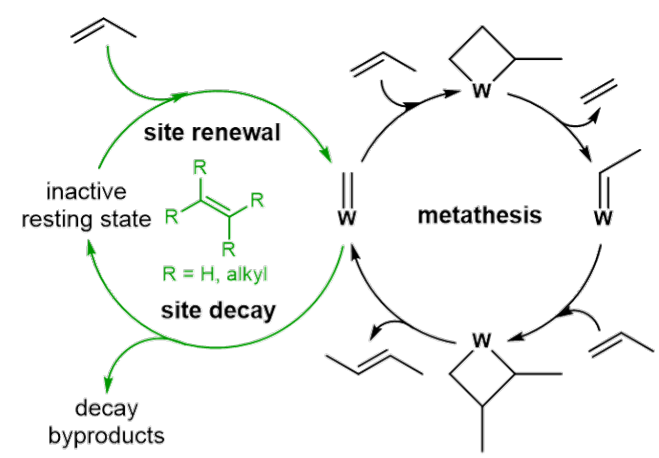

\begin{tabular}{|c|c|}
\hline Promoter (mol\%) & Promotion factor \\
\hline 2-butene $(20 \%)$ & $1.5\left(330^{\circ} \mathrm{C}\right)$ \\
\hline Isobutene $(20 \%)$ & $2.5\left(330^{\circ} \mathrm{C}\right)$ \\
\hline $4 \mathrm{ME}(1.5 \%)$ & $3.8\left(330^{\circ} \mathrm{C}\right)$ \\
\hline $\mathrm{i} 4 \mathrm{ME}(1.5 \%)$ & $4.6\left(330^{\circ} \mathrm{C}\right)$ \\
\hline $\mathrm{i} 4 \mathrm{ME}(1.5 \%)$ & $30\left(250^{\circ} \mathrm{C}\right)$ \\
\hline
\end{tabular}

Fig. 1. Promotion of heterogeneous olefin metathesis by manipulating site renewal and decay. (Top) Schematic illustrating the relationship between steady-state Chauvin cycle metathesis and promoter-controlled site renewal/site decay. W represents a silica-supported mononuclear tungsten active site where the support has been omitted for clarity. (Bottom) Promotional effect of various co-fed olefins on propylene metathesis rates (4ME: 2,3-dimethyl-2-butene, i4ME: 2,3dimethyl-1-butene). The promotion factor is defined as the steady-state product formation rate in the presence of promoter divided by the steady-state product formation rate without promoter. Methods of promoter introduction and full experimental details are provided in the SI. Reaction conditions: $10 \mathrm{mg} \mathrm{3 \% SOMC}$ pretreated at $550^{\circ} \mathrm{C}$ under $100 \mathrm{~mL} / \mathrm{min}$ He for $1 \mathrm{~h}, 50 \mathrm{~mL} / \mathrm{min}$ total gas flow rate $\left(50 \% \mathrm{C}_{3} \mathrm{H}_{6}\right.$ with balance $\left.\mathrm{He}\right)$, WHSV $=0.0019 \mathrm{~mol} \mathrm{C}_{3} \mathrm{H}_{6} / \mathrm{g}_{\text {cat. }}$. . 

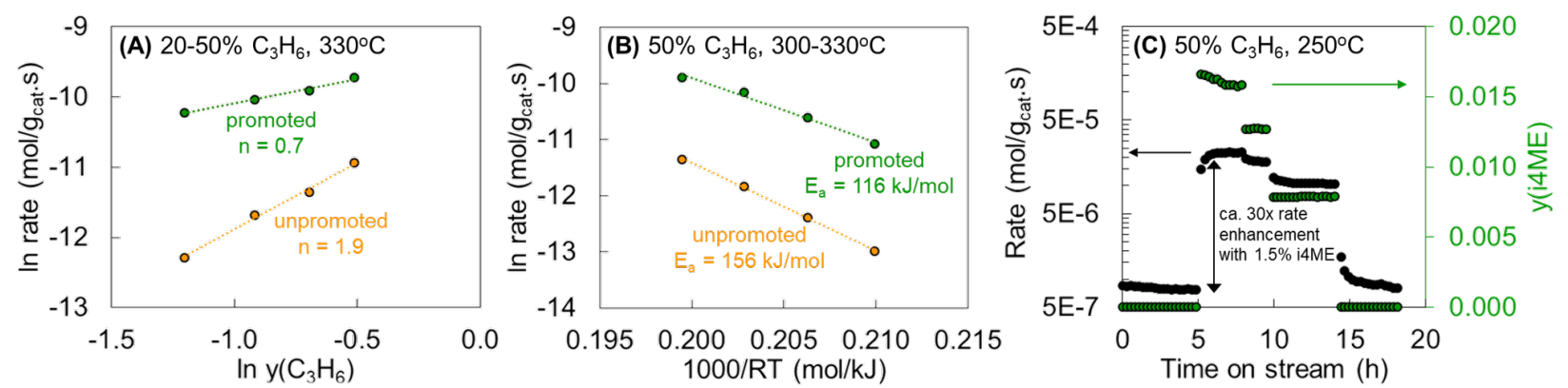

Fig. 2. Effect of co-fed promoters on propylene metathesis activity and kinetics. (A) Reaction order plots of propylene metathesis without promoter (orange) and with promoter $(1.0 \mathrm{~mol} \% 4 \mathrm{ME}$ $+0.5 \mathrm{~mol} \% \mathrm{i} 4 \mathrm{ME}$, green). (B) Arrhenius plots of propylene metathesis without promoter (orange) and with promoter $(1.0 \mathrm{~mol} \% 4 \mathrm{ME}+0.5 \mathrm{~mol} \%$ i4ME, green). (C) Effect of promoter cycling on metathesis activity. Reaction conditions: $10 \mathrm{mg} \mathrm{3 \% SOMC} \mathrm{pretreated} \mathrm{at} 550^{\circ} \mathrm{C}$ under $100 \mathrm{~mL} / \mathrm{min}$ He for $1 \mathrm{~h}, 50 \mathrm{~mL} / \mathrm{min}$ total gas flow rate (propylene + balance He or He saturated with promoter, propylene concentration and temperature are indicated in each subplot). Full experimental details are provided in the SI. 

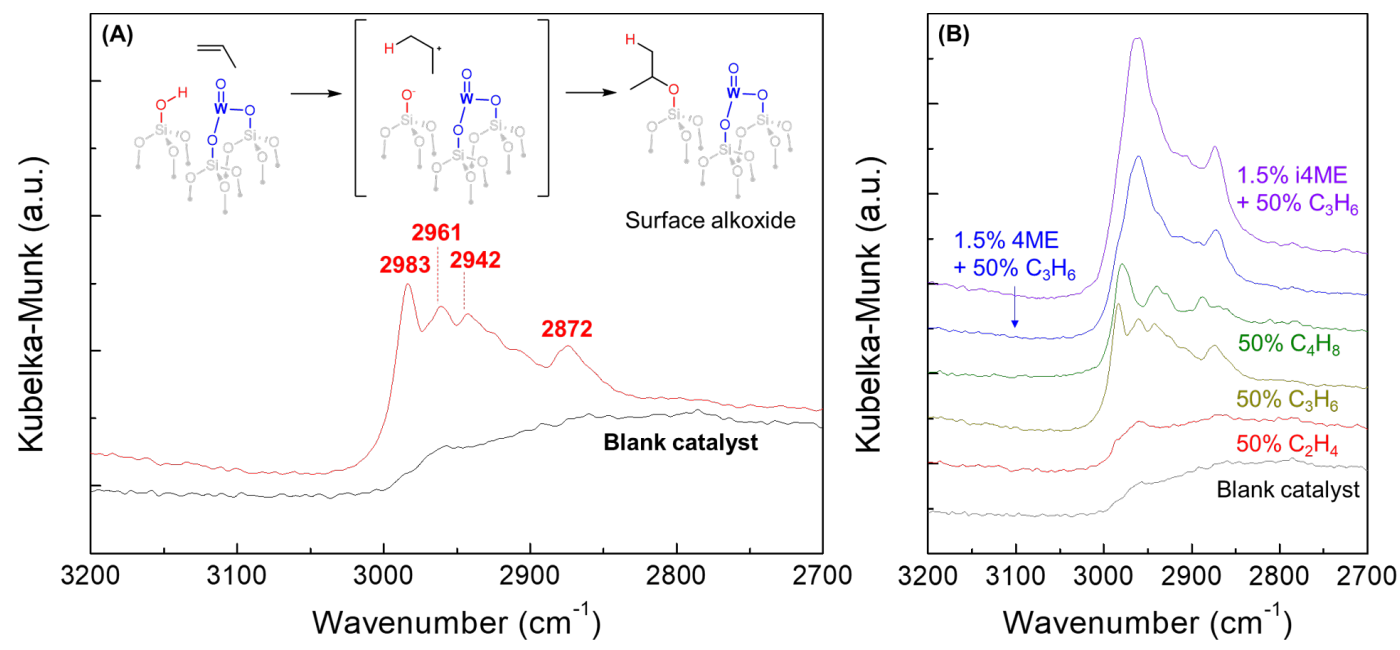

Fig. 3. DRIFTS studies of olefin chemisorption on spent catalyst. (A) DRIFTS spectrum of propylene chemisorbed on spent $3 \% \mathrm{SOMC}$ at $50^{\circ} \mathrm{C}$. The formation of surface alkoxide species proposed to be responsible for the observed peaks is shown in the inset. (B) DRIFTS spectra of various olefins chemisorbed on spent $3 \% \mathrm{SOMC}$ at $50^{\circ} \mathrm{C}$, superimposed on the same axes to illustrate intensity differences. Each spectrum is plotted separately with peaks labeled in Fig. S17, and full experimental details are provided in the SI. 


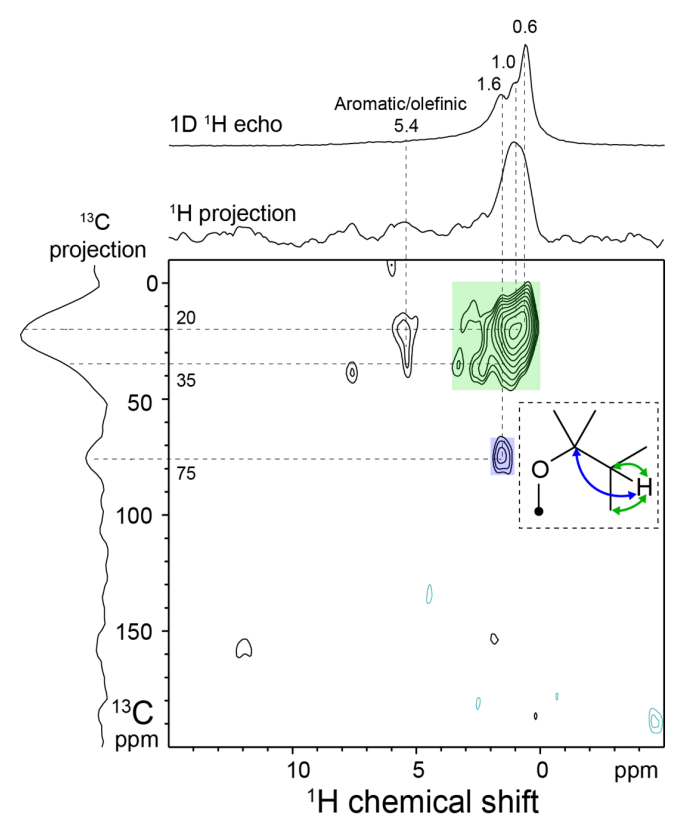

Fig. 4. Solid-state 2D ${ }^{1} \mathbf{H}\left\{{ }^{13} \mathrm{C}\right\}$ D-HMQC NMR correlation spectrum of spent catalyst contacted with propylene and i4ME. The spectrum was acquired at $9.4 \mathrm{~T}, 298 \mathrm{~K}, 40 \mathrm{kHz}$ MAS, and with dipolar recoupling periods of 60 rotor periods $(1.5 \mathrm{~ms})$. The $1 \mathrm{D}{ }^{13} \mathrm{C}$ or ${ }^{1} \mathrm{H}$ projections of the $2 \mathrm{D}$ spectrum are shown along the ordinate and abscissa, respectively, and a $1 \mathrm{D}{ }^{1} \mathrm{H}$ echo spectrum acquired under the same conditions is shown for comparison. The schematic inset shows ${ }^{1} \mathrm{H}-{ }^{13} \mathrm{C}$ interactions on a surface alkoxide consistent with the observed correlated signal intensities (green and blue shaded regions). Full sample preparation and measurement details are provided in the SI. 


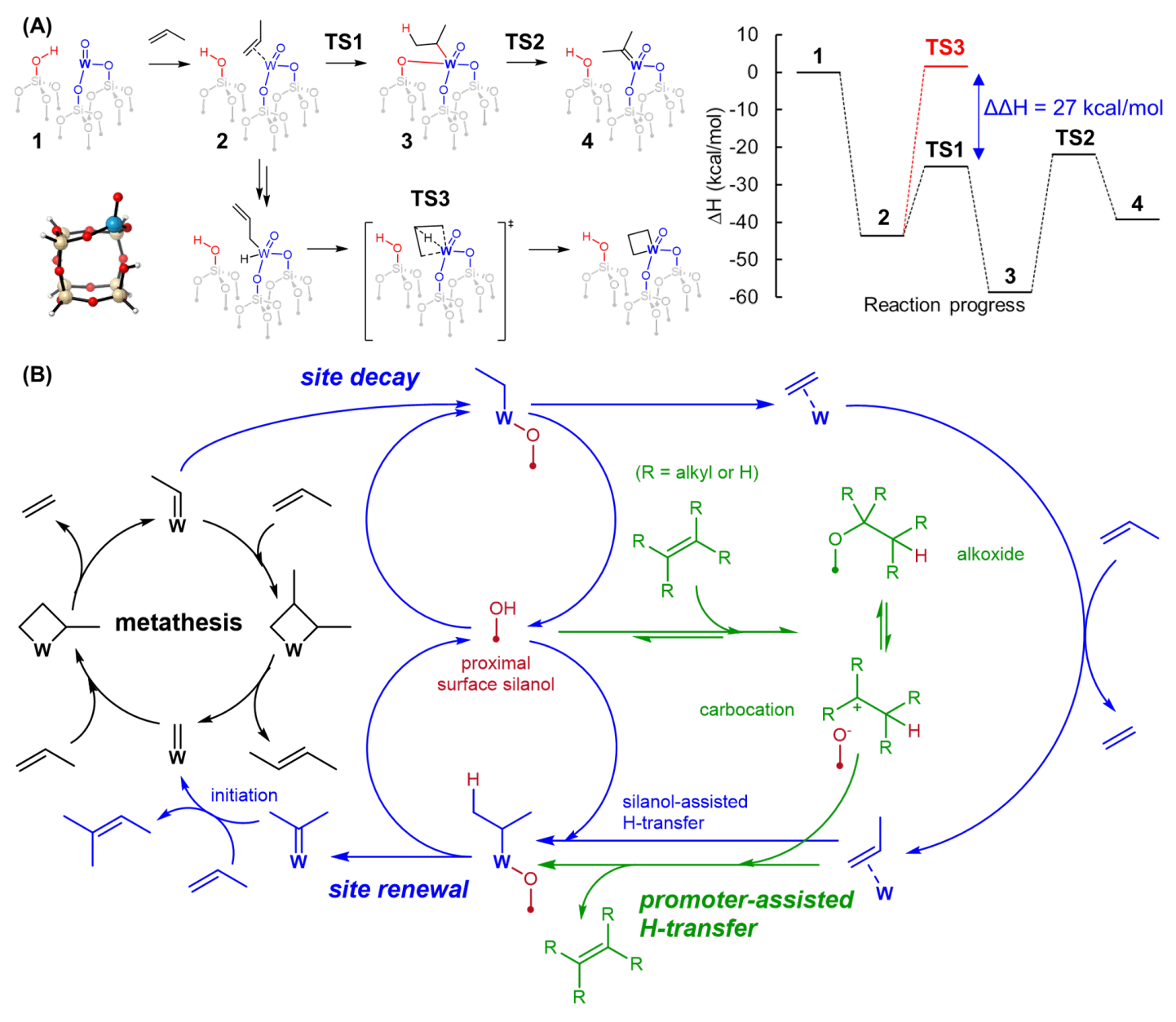

Fig. 5. Proposed mechanisms for site renewal, site decay and promotion. (A) Comparison of the proposed silanol-catalyzed 1,2-proton shift (top; 1 to 4 ) and the classical allylic C-H activation/ $\beta$-hydrogen transfer (bottom; TS3) pathways for site renewal. Density functional theory calculations of these pathways confirm that appropriately positioned silanol groups can effectively catalyze alkylidene formation. The silsesquioxane cluster model used is shown in the bottom left ( $\mathrm{Si}$ : beige, W: blue, O: red, $\mathrm{H}$ : white). Reported energy values are enthalpies at $350^{\circ} \mathrm{C}$ relative to infinitely separated 1 and propylene (full computational details in SI). (B) Proposed catalytic cycle integrating metathesis with in situ silanol-catalyzed site renewal and decay and promoter-assisted proton transfer. $\mathbf{W}$ represents a silica-supported mononuclear tungsten active site where the support has been omitted for clarity. 


\section{References:}

1. Ivin, K. J.; Mol, J. C., Olefin Metathesis and Metathesis Polymerization. Academic Press: 1997.

2. Mol, J., Industrial applications of olefin metathesis. J. Mol. Catal. A: Chem. 2004, 213 (1), 39-45.

3. Sattler, J. J.; Ruiz-Martinez, J.; Santillan-Jimenez, E.; Weckhuysen, B. M., Catalytic dehydrogenation of light alkanes on metals and metal oxides. Chem. Rev. 2014, 114 (20), 1061310653.

4. Agarwal, A.; Sengupta, D.; El-Halwagi, M., Sustainable process design approach for onpurpose propylene production and intensification. ACS Sustainable Chem. Eng. 2018, 6 (2), 2407-2421.

5. Grant, J. T.; Carrero, C. A.; Goeltl, F.; Venegas, J.; Mueller, P.; Burt, S. P.; Specht, S. E.; McDermott, W. P.; Chieregato, A.; Hermans, I., Selective oxidative dehydrogenation of propane to propene using boron nitride catalysts. Science 2016, 354 (6319), 1570-1573.

6. $\quad$ Tian, P.; Wei, Y.; Ye, M.; Liu, Z., Methanol to olefins (MTO): from fundamentals to commercialization. ACS Catal. 2015, 5 (3), 1922-1938.

7. Global Propylene Market. IHS Markit: 2014.

8. Propylene Market. IRPC: 2015.

9. $\quad$ Lwin, S.; Wachs, I. E., Olefin Metathesis by Supported Metal Oxide Catalysts. ACS Catal. 2014, 4 (8), 2505-2520.

10. Jean-Louis Hérisson, P.; Chauvin, Y., Catalyse de transformation des oléfines par les complexes du tungstène. II. Télomérisation des oléfines cycliques en présence d'oléfines acycliques. Die Makromolekulare Chemie: Macromolecular Chemistry and Physics 1971, 141 (1), 161-176.

11. Hoveyda, A. H.; Zhugralin, A. R., The remarkable metal-catalysed olefin metathesis reaction. Nature 2007, 450 (7167), 243.

12. Amakawa, K.; Wrabetz, S.; Krohnert, J.; Tzolova-Muller, G.; Schlogl, R.; Trunschke, A., In situ generation of active sites in olefin metathesis. J. Am. Chem. Soc. 2012, 134 (28), 1146273.

13. Howell, J. G.; Li, Y.-P.; Bell, A. T., Propene metathesis over supported tungsten oxide catalysts: A study of active site formation. ACS Catal. 2016, 6 (11), 7728-7738.

14. Handzlik, J.; Kurleto, K.; Gierada, M., Computational Insights into Active Site Formation during Alkene Metathesis over a MoOx/SiO2 Catalyst: The Role of Surface Silanols. ACS Catal. 2021, 13575-13590.

15. Mougel, V.; Chan, K.-W.; Siddiqi, G.; Kawakita, K.; Nagae, H.; Tsurugi, H.; Mashima, K.; Safonova, O.; Copéret, C., Low Temperature Activation of Supported Metathesis Catalysts by Organosilicon Reducing Agents. ACS Cent. Sci. 2016, 2 (8), 569-576.

16. Ding, K.; Gulec, A.; Johnson, A. M.; Drake, T. L.; Wu, W.; Lin, Y.; Weitz, E.; Marks, L. D.; Stair, P. C., Highly efficient activation, regeneration, and active site identification of oxidebased olefin metathesis catalysts. ACS Catal. 2016, 6 (9), 5740-5746.

17. Michorczyk, P.; Węgrzyniak, A.; Węgrzynowicz, A.; Handzlik, J., Simple and Efficient Way of Molybdenum Oxide-Based Catalyst Activation for Olefins Metathesis by Methane Pretreatment. ACS Catal. 2019, 9, 11461-11467.

18. Yamamoto, K.; Chan, K. W.; Mougel, V.; Nagae, H.; Tsurugi, H.; Safonova, O. V.; Mashima, K.; Copéret, C., Silica-supported isolated molybdenum di-oxo species: formation and 
activation with organosilicon agent for olefin metathesis. Chem. Commun. 2018, 54 (32), 39893992.

19. Lwin, S.; Wachs, I. E., Reaction Mechanism and Kinetics of Olefin Metathesis by Supported ReO x/A12O3 Catalysts. ACS Catal. 2015, 6 (1), 272-278.

20. Lwin, S.; Wachs, I. E., Catalyst Activation and Kinetics for Propylene Metathesis by Supported WO x/SiO2 Catalysts. ACS Catal. 2016, 7 (1), 573-580.

21. Zhao, P.; Ye, L.; Sun, Z.; Lo, B. T.; Woodcock, H.; Huang, C.; Tang, C.; Kirkland, A. I.; Mei, D.; Edman Tsang, S. C., Entrapped single tungstate site in zeolite for cooperative catalysis of olefin metathesis with Brønsted acid site. J. Am. Chem. Soc. 2018, 140 (21), 6661-6667. 22. Coperet, C.; Comas-Vives, A.; Conley, M. P.; Estes, D. P.; Fedorov, A.; Mougel, V.; Nagae, H.; Nunez-Zarur, F.; Zhizhko, P. A., Surface organometallic and coordination chemistry toward single-site heterogeneous catalysts: strategies, methods, structures, and activities. Chem. Rev. 2016, 116 (2), 323-421.

23. Poater, A.; Solans-Monfort, X.; Clot, E.; Coperet, C.; Eisenstein, O., Understanding d0olefin metathesis catalysts: Which metal, which ligands? J. Am. Chem. Soc. 2007, 129 (26), 8207-8216.

24. Luckner, R. C.; Wills, G. B., Transient kinetics of the disproportionation of propylene over a tungsten oxide on silica catalyst. J. Catal. 1973, 28 (1), 83-91.

25. Pennella, F.; Banks, R. L., The influence of chelating polyolefins on the disproportionation of propylene catalyzed by WO3 on silica. J. Catal. 1973, 31 (2), 304-308. 26. Chatterjee, A. K.; Choi, T.-L.; Sanders, D. P.; Grubbs, R. H., A general model for selectivity in olefin cross metathesis. J. Am. Chem. Soc. 2003, 125 (37), 11360-11370.

27. Chan, K. W.; Mance, D.; Safonova, O. V.; Copéret, C., Well-Defined Silica-Supported Tungsten (IV)-Oxo Complex: Olefin Metathesis Activity, Initiation, and Role of Brønsted Acid Sites. J. Am. Chem. Soc. 2019, 141 (45), 18286-18292.

28. Gangwal, S. K.; Wills, G. B., Effects of ammonia and amines on propylene disproportionation over a tungsten oxide silica catalyst. J. Catal. 1978, 52 (3), 539-541.

29. Fathikalajahi, J.; Wills, G. B., Effects of ammonia upon propylene metathesis over a WO3/SiO2 catalyst. J. Mol. Catal. 1980, 8 (1-3), 127-134.

$3030 . \quad$ Van Roosmalen, A.; Mol, J., Active centers for the metathesis and isomerization of alkenes on tungsten-oxide/silica catalysts. J. Catal. 1982, 78 (1), 17-23.

31. Noh, G.; Lam, E.; Bregante, D. T.; Meyet, J.; Šot, P.; Flaherty, D. W.; Copéret, C., Lewis Acid Strength of Interfacial Metal Sites Drives $\mathrm{CH} 3 \mathrm{OH}$ Selectivity and Formation Rates on $\mathrm{Cu}-$ Based CO2 Hydrogenation Catalysts. Angew. Chem. Int. Ed. 2021, 60 (17), 9650-9659.

35 32. Freundlich, J. S.; Schrock, R. R.; Cummins, C. C.; Davis, W. M., Organometallic Complexes of Tantalum That Contain the Triamidoamine Ligand,[(Me3SiNCH2CH2) 3N] 3-, Including an Ethylidene Complex Formed via a Phosphine-Catalyzed Rearrangement of an Ethylene Complex. J. Am. Chem. Soc. 1994, 116 (14), 6476-6477.

33. Hirsekorn, K. F.; Veige, A. S.; Marshak, M. P.; Koldobskaya, Y.; Wolczanski, P. T.; 40 Cundari, T. R.; Lobkovsky, E. B., Thermodynamics, Kinetics, and Mechanism of (silox) 3M (olefin) to (silox) 3M (alkylidene) Rearrangements (silox=tBu3SiO; $\mathrm{M}=\mathrm{Nb}, \mathrm{Ta}) . J$. Am. Chem. Soc. 2005, 127 (13), 4809-4830.

34. Liu, S.; Boudjelel, M.; Schrock, R. R.; Conley, M. P.; Tsay, C., Interconversion of Molybdenum or Tungsten d2 Styrene Complexes with d0 1-Phenethylidene Analogues. J. Am. Chem. Soc. 2021, 143 (41), 17209-17218. 
35. Taylor, J. W.; Schrock, R. R.; Tsay, C., Molybdenum Disubstituted Alkylidene Complexes. Organometallics 2020, 39 (5), 658-661.

\section{Acknowledgements}

The computations were performed on the Euler cluster at ETH Zurich (ETHZ). The authors acknowledge Husain Adamji and Jie Zhu for help in the synthesis and characterization of the WI $\mathrm{MoO}_{\mathrm{x}} / \mathrm{SiO}_{2}$ catalyst, Thejas $\mathrm{S}$. Wesley for a careful reading of the manuscript and Prof. Richard R. Schrock for fruitful discussions. Funding: The work at MIT was financially supported by Saudi Aramco through MIT Energy Initiative (Grant No. 6930839) and the U.S. Department of Energy, Office of Basic Energy Sciences under Award DE-SC0016214. The ETHZ authors are grateful to the Swiss National Science Foundation (SNF) for financial support of this work (grant no. 200021L_157146). Z.J.B. also gratefully acknowledges financial support from the SNF (Spark award CRSK-2_190322). Author contributions: D.F.C., S.K.S., C.C. and Y.R.-L. conceptualized the project. Y.R.-L. supervised the project. Z.J.B. and K.W.C. performed the synthesis and characterization of the SOMC catalysts. Z.J.B. conducted the solid-state NMR analyses. T.Z.H.G., R.Z. and J.H.K. performed all other experiments and data analyses at MIT. T.Z.H.G. designed and performed the computational studies. T.Z.H.G. wrote the manuscript with input from all other authors. Competing interests: D.F.C., S.K.S., and Y.R.-L. are inventors on a patent application that covers the use of olefin promoters for heterogeneous metathesis. Data and materials availability: All data is available in the manuscript or the supplementary materials.

\section{Supplementary Materials:}

Materials and Methods

Figures S1-S23

Tables S1-S3

25 References

Excel file of computed absolute energies in Hartrees

Zip file of Cartesian coordinates of optimized geometries 